\title{
A PESCA DO CAMARÃO COMO UMA PRÁTICA EDUCATIVA NO PROJETO DE ASSENTAMENTO AGROEXTRATIVISTA NOSSA SE- NHORA DO LIVRAMENTO ILHA TABATINGA, ABAETETUBA-PA
}

THE FISHING OF SHRIMP AS AN EDUCATIVE PRACTICE IN THE AGRO-EXTRATIVE SETTLEMENT PROJECT OUR LADY OF DELIVERANCE TABATINGA ISLAND - ABAETETUBA/PARÁ

\section{Elza Ferreira Baia ${ }^{1}$}

RECEBIDO: 12/08/2019 | ACEITO: 09/01/2019

DOI: $10.5902 / 2317175834732$

\section{RESUMO}

O artigo discute a produção artesanal da pesca de camarão praticada por ribeirinhos no Projeto de Assentamento Agroextrativista Nossa Senhora do Livramento - Ilha Tabatinga, Abaetetuba-PA, cuja ação motiva processos culturais e aprendizagem entre os sujeitos, destacando a passagem do saber entre as gerações. Buscou-se compreender como funciona o processo de reprodução do saber enquanto uma prática educativa exercida por moradores locais, o que exigiu adentrar na realidade do fazer produtivo e de subsistência da comunidade local. Através da pesquisa foi possível formular possibilidades de cunho reflexivo sobre as relações entre a produção familiar e o processo educativo que ocorre no âmbito das escolas do campo. O estudo direcionou-se pela pesquisa qualitativa, cujos pressupostos de base científica ancoram-se nas ciências sociais, incluindo no caminho metodológico o trabalho de campo, com uso de entrevistas e outras formas de coleta de dados. A partir da análise dos resultados obtidos, foi possível identificar que a prática artesanal da pesca apresenta uma diversidade de conhecimentos, bem como é mediada pelo uso dos recursos naturais que alicerçam a vida, garante uma forma de sustentabilidade ambiental e familiar. Além disso esse saber-fazer possibilita pensar em outros caminhos para a construção de uma educação protagonizada na realidade e pelos sujeitos.

Palavras-Chave: Prática Educativa; Pesca; Produção; Ribeirinhos; Saber.

1 Estudante curso de Especialização Lato Sensu em Educação do Campo e Extensão Rural pela Universidade Federal do Pará/Campus de Abaetetuba 


\section{ABSTRACT}

The article brings as a discussion the Craft production shrimp fishery practiced by riverside in the Agroextrativist Settlement Project Our lady of Deliverance - Tabatinga Island, Abaetetuba-PA, whose action provokes cultural and learning processes among the subjects, highlighting the passage of knowledge between the generations. It was sought to understand how the process of reproduction of knowledge occurs as an educational practice practiced by local residents, demanding to enter into the productive and subsistence reality of the local community and, with the study, dare to indicate reflective possibilities about the relations between family production and the educational process that takes place in the field schools. The study was guided by qualitative research, whose scientifically based assumptions are anchored in the social sciences, including in the methodological path the fieldwork, using interviews and other forms of data collection. From the analysis of the results obtained it was possible to identify that the practice of artisan. fishing presents a diversity of knowledge and is mediated by the use of natural resources that sus th

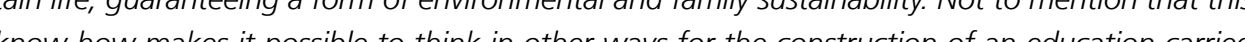
know-how makes it possible to think by the subjects.

Keyword: Educational practice; Fishing; Production; Riverside; To know

\section{Introdução}

O presente artigo aborda a produção artesanal da pesca do camarão praticada por ribeirinhos no Projeto de Assentamento Agroextrativista Nossa Senhora do Livramento - Ilha Tabatinga, Abaetetuba-PA ${ }^{3}$. Partindo da premissa de que tal atividade produtiva constitui-se uma prática educativa ${ }^{4}$, houve necessidade de conhecer os fazeres-saberes dessa produção bem como a forma de subsistência dos moradores locais. O saber-fazer diz respeito ao "saber do ofício" de "agentes populares de trabalho simbólico" (BRANDÃO, 2009, p. 13). Assim, o estudo pauta os processos de reprodução do saber que, de alguma forma, constituem-se práticas educativas desenvolvidas na comunidade em geral e estão para além da formalização ensino-escola.

Abaetetuba-PA é um município composto por quarenta e nove áreas agrícolas, situadas em estradas e ramais, setenta e duas ilhas, uma vila ${ }^{5}$ e dezesseis bairros urbanos, formando uma população estimada em $153.380 \mathrm{mil}$ habitantes (IBGE, 2017). Especialmente, os rios, furos e igarapés marcam um cenário paisagístico e cultural que compõem o território das ilhas do município, agregando aproximadamente 50 mil habitantes. O lócus da pesquisa, a ilha Tabatinga, vivem 130 famílias assentadas da Reforma Agrária, que estão 3 Este Projeto faz parte do Plano Nacional de Reforma Agrária-PNRA, sendo reconhecido em 27/07/2004

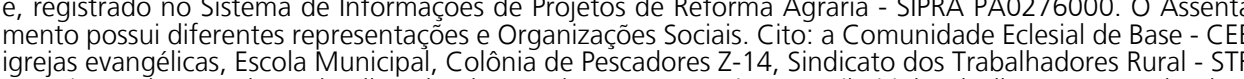

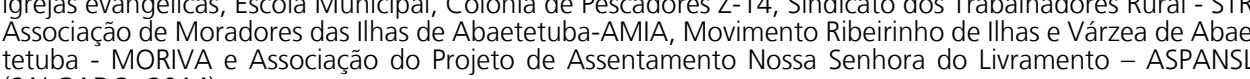
4 Alem dessa produção, as pessoas dessa comunidade sobrevivem da agricultura familiar, do extrativismo
do açái e de outras formas de trabalho. Também, existem moradores que são assalariados oriundos do funcionalismo público, de aposentadorila, de programas sociais (bolsa familia, seguro defeso e bolsa verde. 5 Trata-se da Vila de Beja, a qual já foi chamada de Mortiguar, Samaúma e Guerra, nomes atribuídos pelo
Padre rancisco Xavier de Mendonşa, no século XVIII, também foi considerada o berço da história de Abae-
tetuba (MACHADO, 1986, p. 17). divididas em três áreas: o rio Jarumã, a Costa Tabatinga e o Furo do Boto, os quais se limitam com o rio Maratauíra ${ }^{6}$. Esta ilha é um lugar de "construção identitária" (POJO, 2017, p. 86) que comporta muitos saberes, produções materiais e imateriais cujas finalidades é a sobrevivência sustentável a nível socioeconômico e também em termos culturais, por meio de suas gentes. Esses aspectos foram indagados e observados no cotidiano da comunidade, por um período de três meses; percorrendo as práticas do cotidiano do Assentamento, especialmente focalizando os processos do saber-fazer da pesca de camarão junto as famílias e as interações realizadas com outras pessoas sob a forma de conversas informais, durante as travessias ao lugar entre outros.

As práticas educativas de um determinado lugar ocorrem em momentos, situações e modos diferentes entre sujeitos, as quais são perpassadas por meio de trocas simbólicas ${ }^{7}$, de experiências e de investidas de caráter interativo e relacional, tal como acontece no espaço da escola, da comunidade ou de alguma organização social. Nesse sentido, os saberes locais de llha Tabatinga situam práticas produtivas do extrativismo do açaí e da pesca artesanal, em especial, a da pesca do camarão, compondo o dia a dia do trabalho e da produção da vida dos ribeirinhos. Sobre esse enfoque, a dimensão dos processos culturais em modos de produzir, se faz relevante no debate, pois, através de tais práticas eles "[...] estabelecem as regras e os processos de reprodução de valores $\mathrm{e}$ conhecimentos que dizem o que são, entre quem se repartem, a quem servem e como devem ser realizados a vida e seus trabalhos" (BRANDÃO, 2009, p. 33).

Partindo da ideia de que o processo educativo é algo que move uma sociedade no sentido de intercambiar conhecimentos e de auxiliar na compreensão do modo de vida dos sujeitos de um local específico, a investigação procurou compreender como se dá o processo de reprodução do saber na produção familiar da pesca do camarão enquanto uma prática educativa exercida pelos moradores locais. Com base nessa questão, o estudo teve como objetivo investigar a produção familiar praticada por meio da pesca do camarão no PAE Nossa Senhora do Livramento, buscando identificar como as práticas educativas se processam entre os moradores e algumas famílias, adentrando na realidade do fazer produtivo e de subsistência e, com o estudo ousar indicar possibilidades de cunho reflexivo sobre as relações entre a produção familiar e o processo educativo escolar. Nesses termos, o trabalho encontra-se estruturado da seguinte forma: aspectos teóricos e metodológicos; a territorialidade da prática social no contexto da pesquisa e a descrição dos saberes do povo ribeirinho da comunidade pesquisada.

6 Fonte: Registro de Beneficiáríos-RB, INCRA, 2015 pilotar a canoa aos quatro anos de idade. Significica dizer, tomando as idelias de Brandana (2009) ) ade ou pilotar a canoa aos quatro anos de idade. Significa dizer, tomando as ideias de Brandão (2009) que os
criadores populares individuais e coletitos possuem cultura - aquilo que reflete para eles a continuidade de
seu peculiar modo de vida, isto é, suas experiencias sociais e simbolicas da vida. 


\section{Referencial teórico e o lócus da pesquisa}

Os territórios rurais ou do campo, além de serem espaços geográficos, são espaços-lugares socioculturais, cujas práticas sociais desencadeiam a concretude das relações de poder entre os sujeitos e seu espaço, entre meandros fronteiriços cidade-campo e, ao mesmo tempo, elucidam a rica diversidade que se encontra na Amazônia fazendo dela uma região rica em potencial cultural, social, paisagístico e econômico. A região amazônica concentra particularidades e exuberâncias que a diferencia de outras regiões do Brasil e do mundo, ressaltando que o território ribeirinho é um bioma que agrupa diferentes vidas e espécies da fauna e da flora. Ele agrega diversos grupos sociais como os povos ditos de indígenas, caiçaras, agricultores familiares, quilombolas, pescadores, extrativistas, ribeirinhos. No caso de Abaetetuba, ele possu um conjunto de ilhas, banhadas por rios, furos e igarapés, que se subdivide em pequenos territórios (pedaços de terra) intitulados de ilhas, cuja referência histórica principal é a de ser comunidade tradicional ou em uma linguagem mais atual, de comunidade tradicional do tipo Assentamento ${ }^{\circ}$

Diegues (2004), aponta que uma comunidade tradicional diz respeito ao "espaço coletivo" de povos tradicionais e que estão sintonizados com a rica "biodiversidade", como é o caso da relação construída entre humano-natureza nos ribeirinhos de Abaetetuba-PA. No dizer do autor,

Essas comunidades tradicionais têm também uma representação simbólica desse espaço que thes fornece os meios de subsistência, os meios de trabalho e produção e os meios de produzir os aspectos materiais das relaçōes sociais, isto é, os que compõem a estrutura de uma sociedade (relações de parentesco etc) (DIEGUES, 2004, p. 65).

As ilhas apresentam áreas com características ambientais diferentes, como os ambientes de terra-firme e o de várzea e, possuem uma fauna vegetal diversificada. As áreas de terra-firme são consideradas mais altas e densas, dificultando o alagamento do solo, enquanto a área de várzea é formada por um solo constantemente alagado na maior parte do ano. Nesse ambiente também são encontradas diversas espécies de vegetais, típicas dos tipos de solos, sendo de "[...] tipos e de variações em uma mesma espécie ou entre espécies diferentes de plantas de terras firmes e de várzea, de peixes, de animais de caça etc.", que são essenciais ao processo sustentável do ambiente pelos ribeirinhos e, do sistema produtivo local (CASTRO, 1998, p. 8). Outra característic da ilha Tabatinga diz respeito a sua especificidade de conhecimento popula sobre aspectos da natureza, como as chuvas que causam variações das espécies animal e vegetal, propício para reprodução e o cultivo; sobre as marés e suas influências, que determinam a pesca, o deslocamento dos moradores pelos

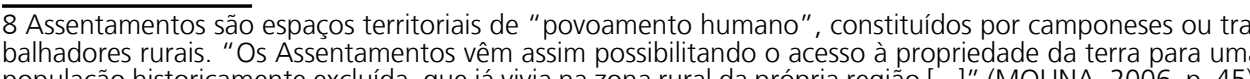
populaçấo historicamente excluída, que já vivivi na zona rural da própria regiáa [...]" (MOLINA, 2006, p. 45). garapés e furos. São conhecedores do tipo de solo de várzea, cujo plantio e a colheita sofrem alterações pelo meio natural do local.

Outra distinção na vida dos ribeirinhos são as imbricações com o 'mundo das águas' e seus rios, os quais são os principais meios utilizados para deslocamento das pessoas e importantes também no escoamento da produção agrícola. Essa paisagem e forma natural de rios e de áquas "[...] é também um cenário de interações positivas entre os moradores, a partir do que lhes é comum" (POJO, 2017, p. 70). O rio determina caminhos e também sofre influência do "regime das marés" (SALGADO, 2014, p. 35), funciona como "símbolo, no ciclo da vida amazônica" (POJO, 2017, p. 72), por ser um sinalizador da vida ribeirinha, agregando todo um ritmo cultural à população local e vice-versa. As rabetas, rabudos, canoas, cascos e voadeiras são embarcações utilizadas pelos moradores dentro e nos arredores, entre os rios Tabatinga, Jarumã e Maratauíra que banham a ilha. Normalmente, o transcurso da ilha até a beira da cidade gasta em média de 05 a 10 minutos.

O modo de vida ribeirinho tem em si peculiaridades geradores de sobrevivência e sustentabilidade dos próprios moradores locais, pois eles estão embrenhados por saberes e dinâmicas sociais que adentram o cotidiano das famílias. No geral, o que é praticado ou produzido por esses sujeitos tem finalidades próprias de uso habitual, desse modo, a pesca é uma prática do saber-fazer artesanal, presente por muitas gerações nas famílias ribeirinhas, nas quais os tipos de atividades pesqueiras evidenciam uma diversidade de saberes acumulados por esses sujeitos. Pojo (2013), em umas de suas pesquisas em comunidade rural de Abaetetuba, traz alguns significados muito próximos dos vividos por moradores da llha Tabatinga, quando afirma que:

Nessas comunidades estão presentes saberes e formas culturais produzidas pelas práticas sociais como o cultivo e o manejo do açaí, a produção de diversos tipos de farinha, o uso versátil do miritit, a feitura da roça, as atividades de pesca e, inclusive, a antiga forma de pescar camarão com matapi, a rica produção artesanal; dominam regras de fabricação e uso de utensílios como o matapi, a peconha, a rede de pesca entre outros (POJO, 2013, p. 169-170).

Outro entrelaçamento do viver de moradores ribeirinhos trata-se dos usos e articulações com a beira da cidade ${ }^{9}$. Configura-se em um espaço especí fico que circula além de saberes, circula modos econômicos, sociais e culturais com base na produção agrícola e extrativa. É onde cria e recria as relações de pertencimento do povo com o lugar. Nela, pode ser visto um jeito de integrar campo-cidade, através da venda das produções agrícolas, de base familiar de ribeirinhos, assentados e quilombolas, movimentando o comércio local. Em síntese, a beira é um espaço agregador de valores e de trocas, negociações, de sabores e saberes por diferentes sujeitos.

9 A beira da cidade, é o lugar onde acontece a comercialização da produção dos ribeirinhos, agricultores
familiares de Abaetetuba. A beira é também conhecida como orla ou o porto da cidade. 
No caso dos ribeirinhos onde ocorreu a investigação, eles têm como base econômica a produção familiar para o sustento, para o consumo e o excedente para comércio. A principal fonte de renda advém da pesca artesanal do peixe do camarão e do extrativismo do açaí e do miriti, a criação de pequenos animais e a colheita de frutas encaixa-se como complemento. Todas as atividades citada são características do ambiente encharcado ${ }^{10}$ pelas águas que margeia a ilha

Toda essa experiência com as águas, de mobilidade pelos rios, furos e igarapés e, ainda, com a terra e a mata, foi determinante para os povos aprenderem a lidar com a natureza. Dessa forma, foram e ainda são produzidos saberes em dimensões diversas e que advém de seus antepassados, herdeiros (as) de saberes e produtores (as) de conhecimentos, justificando que "A cultura é a alma de um povo" (CPT; MORIVA, 2009, p. 3). No caso dos ribeirinhos, sua cultura é que os identifica como sujeitos lutadores, históricos, possuidores e criadores de identidades próprias. Nas relações dos ribeirinhos com as atividades produtivas, diante do "modo de vida" da llha Tabatinga, na interpretação de Salgado (2014, p. 53) estão manifestas ricas tradições, costumes, religiosidade. Através destas relações sociais são estabelecidas de maneira natural, identificando-se como relevante ao desenvolvimento social, sustentável e local dos sujeitos.

A produção familiar é a principal forma de trabalho e a geradora de subsistência dos povos do campo. É através desta forma produtiva, relacionada com os recursos naturais das matas e rios, que os territórios rurais de ilhas de Abaetetuba, como é o caso da llha Tabatinga, produzem suas vidas e se organizam. A agricultura familiar de um modo geral na Amazônia paraense caracteriza-se como uma importante forma de organização da produção que associa família, produção e trabalho nos diversos ambientes de produção terrestre e aquático (FRAXE, 2007, p. 56). Ela é a base do patrimônio cultural e econômico dos sujeitos camponeses. Produzem para manutenção de suas famílias e para o sustento de cidades próximas - na região tocantina; por isso se faz importante a defesa, não somente da produção de alimentos em grande quantidades, mas da plantação e produção de alimentos de qualidade com base orgânica de incentivo agroecológico. Para isso, é preciso o investimento em políticas públicas de fortalecimento e valorização da produtividade dos camponeses na perspectiva da agroecologia.

Assim, a prática educativa vivenciada por sujeitos do campo encontra-se representada por uma diversidade de saberes locais e pela contínua produção familiar no cotidiano dos lugares e espaços que se diversificam nas práticas sociais em torno dos roçados, das águas, das matas, das beiradas dos igarapés e furos. Ta assertiva evidencia que o processo educativo pode acontecer em tais espaços-lugares e, também, na escola até porque, como afirma Arroyo e Fernandes:

O tempo social dos indivíduos, das famílias, das comunidades está vinculado aos tempos da natureza, da produção. As festas, os encontros, as relações entre homem, mulher, entre crianças

10 Trata-se do ambiente de várzea, o qual é 'molhado' e úmido pelas águas dos rios ou igarapés. e adultos são inseparáveis dos tempos de produção e reproducão da existência, das relaçôs sociais, produtivas, culturais (ARçăo da existência, das relaçoes sociais,

Na prática social entre indivíduos e momentos educativos são vivenciadas situações de compreensão crítica sobre a realidade vivenciada pelo homem do campo bem como formam-se os entraves, as trocas simbólicas, as negociações entre parentes e vizinhos, a convivência saudável, os conflitos intracomunidade que circulam durante suas produções. Tal especificidade desse cotidiano traduzido no fazer-saber dos sujeitos carece de um olhar compreensivo sobre como se organiza esses processos de educação, pois eles são diversos, simultâneos e ricos de experiências e sabedorias de aprendizado humano e podem ser geradores de problematizações quanto a formas alternativas de sociabilidade humana. Tomando novamente os autores acima referidos, "os processos educativos acontecem fundamentalmente no movimento social, nas lutas, no trabalho, na produção, na família, na vivência cotidiana. E a escola, o que tem a fazer? " (ARROYO \& FERNANDES, 1999, p. 14).

No caso da comunidade Costa Tabatinga as experiências daqueles sujeitos ocorrem em contextos de trabalho e demais práticas sociais. E a escola precisa concretizar sua função social, integrando-se aos movimentos de cultura e produção desses sujeitos, sintonizando-se com os conteúdos dessas experiências e produções para uma contextualização crítica da realidade e, dessa forma, entrar em uma marcha curricular dinâmica e intercultural, cujo modo de fazer articula-se às práticas sociais existentes na comunidade, afinal ali existe uma comunidade de aprendizes. O povo daquela ilha em sua realidade peculiar transmite e veicula uma forma de aprender-ensinar. Nesses termos, o educador Brandão (2009, p. 3), confirma:

Dentro da equipe, mas estabelecendo entre si relações de trocas de saber e de favores mútuos que se realizam à parte, professores e aprendizes do mundo rural fazem e são, eles próprios, as redes vivas de trabalho docente através dos quais o saber necessário de uma fração da cultura camponesa flui e se torna uma tradição atual e acreditada. (BRANDÂO, 2009, p. 3)

A perspectiva é a de uma prática educativa escolar que assume como ponto de partida os conhecimentos e os saberes dos sujeitos do campo, a valorização das práticas culturais e das vivências no campo assume, portanto, seu caráter político e de ação-reflexão. Tais reflexões pautam uma educação do campo que defendemos, concebendo-a na base da luta por uma sociedade com mais igualdade social, cultural e econômica entre povos, inclusive os do campo, os quais a prática dos sujeitos permeia saberes e processos socioculturais.

Ainda, no tocante às questões educacionais desses povos, bem como das formas de desenvolvimento local, trata-se de compreender que a educação é 
forjada a partir dos territórios e dos saberes produzidos. Ambos são substanciais ao processo humano, por este motivo a pesquisa buscou estabelecer uma aproximação entre a prática social e o conhecimento científico, o saber popular e a educação da vida. Esta foi a abordagem escolhida, pois procurou-se por considerações sobre a transformação social e apontar possibilidades para a educação escolar dos sujeitos que vivem, produzem e se educam no campo.

\section{Aspectos Metodológicos}

A investida de pesquisa envolveu os processos, a observação de práticas e a interação com sujeitos camponeses, o que classifica o estudo dentro d abordagem qualitativa, cujos pressupostos de base científica ancoram-se na ciências sociais, pois "trabalha com o universo dos significados, dos motivos, das aspirações, das crenças e dos valores e das atitudes" (MINAYO, 2009, p. 21). No aprofundamento teórico foram utilizadas referências bibliográficas, as quais perpassaram perpassou concepções e análises sobre práticas educativas, território ribeirinho, assentamento, cultura e outros temas pertinentes. Outro enfoque metodológico foi a realização de um trabalho de campo, ainda que de forma inicial, mas fundamental para se problematizar um pouco sobre os fazeres-saberes já que tratou de "uma vivência, ou seja, é um estabelecimento de uma relação produtora de conhecimento, que diferentes categorias de pessoas fazem, realizam" (BRANDÃO, 2007, p. 12). Este consistiu de observações e do recolhimento de dados por meio de entrevistas com moradores e informações contidas no banco de dados do diagnóstico participativo, social econômico e ambiental das unidades de produção familiar dos assentamento agroextrativistas do município de Abaetetuba, cujos dados encontram-se na posse do IDATAM ${ }^{11}$

A participação de seis moradores locais compõe as entrevistas individuais, sendo alguns pescadores artesanais, trabalhadores da pesca do camarão na área Costa Tabatinga; o representante da Colônia de Pescadores Z-14 (Secretaria rio Jarumã), o primeiro e o atual Presidente ${ }^{12}$ da Associação do PAE Nossa Senhora do Livramento. Os indivíduos foram selecionados com o intuito de compreender melhor a atividade da pesca do camarão e suas formas de medição relacional, cultural e produtiva naquela localidade. Outra estratégia utilizada na recolha de dados foi o uso de recursos digitais, como o celular para gravação e para os registros fotográficos com os sujeitos da pesquisa.

Assim, o estudo, cujo ênfase perpassou intersecções entre cultura e o saber popular, pode servir para uma reflexão sobre as práticas sociais de povos

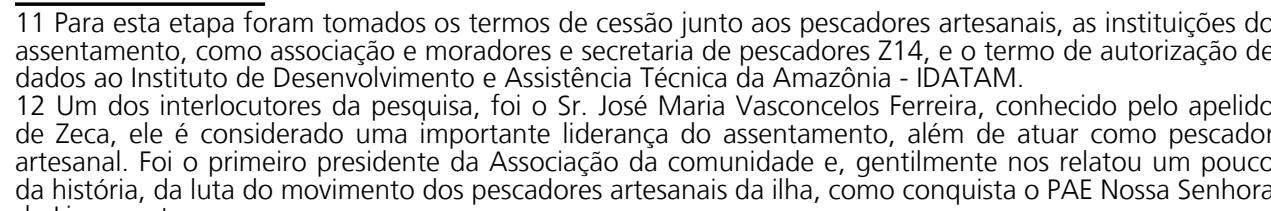

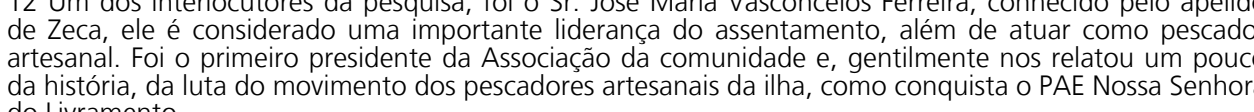

RSh REVITA SOCIAIS \& HUMANAS - VOL. 32 / № 3 - 2019 tradicionais (ribeirinhos) no sentido de problematizar aspectos sociais, econômicos e educacionais A pesquisa poderá contribuir com discussões junto aos profissionais da educação no que diz respeito a educação do campo na região do Baixo Tocantins.

\section{Apresentação e discussão dos resultados}

- Um pouco da história, das lutas e das práticas educativas dos

\section{sujeitos ribeirinhos}

Neste tópico o enfoque são os processos e experiências dos fazeres-saberes percebidos durante um rápido trabalho de campo captando as vozes de alguns ribeirinhos, suas "memórias" (POLLAK, 1992, p. 201). Isto tem por finalidade situar os leitores de suas histórias, suas lutas e suas práticas educativas ditadas, especialmente, nas relações e imbricações que são estabelecidas nos meandros da produção familiar por agricultores. Trata-se da produção familiar praticada por meio da pesca do camarão. Remando pelas narrativas do lugar, foi possível visualizar um pouco sobre a diversidade natural e cultural presentes naquele espaço de vida, do ciclo produtivo e de sustento familiar, isto é, ouvir e observar a "natureza da sabedoria local" (TOLEDO; BARRERA-BASSOLS 2009, p. 16).

Esta ilha, conforme é citado no Plano de Desenvolvimento do Assentamento - PDA (2009), conta que os "habitantes mais antigos" que ocuparam a ilha, parte deles vieram ou são oriundos do nordeste do Brasil. Segundo relatos de moradores, a princípio eram duas as famílias ${ }^{13}$ donas da ilha, as quais foram se desfazendo de parte de suas propriedades, passando a concentrar as terras somente em um grupo familiar, que foi repartindo a propriedade em lotes destinados aos seus filhos. Esses últimos foram se agregando e constituindo suas próprias famílias, desse modo, ocorreu o processo de povoamento do lugar (PDA, 2009, p. 39)

No ano de 1998, os pescadores artesanais da ilha estavam organizados em "coletividade" (POLLAK, 1992, p. 201) constituindo grupos sociais, direcionados a reivindicar e lutar por direitos e pela valorização da classe pescadora. Especialmente, estavam atrás do benefício, seguro defeso ${ }^{14}$, aposentadoria por tempo de trabalho e outros. Em uma das assembleias realizada na colônia de pescadores Z-14, discutiam com a presença da Gerência do Patrimônio da União-GRPU, cuja pauta situava a questão "terra de marinha".

Visando assegurar a garantia de direito à terra, os moradores, legitimaram um grupo de pessoas, representantes da comunidade diante da regularização de suas terras. Esta equipe objetivava exigir o "documento da terra", pois poderiam perdê-la para o turismo ecológico a ser desenvolvido por empresas quase sempre de fora, visto que a "ilha fica muito próximo à cidade, com rios e muitos igarapés" (Seu Zeca, entrevista, 04/2018). Assim, foi escolhi-

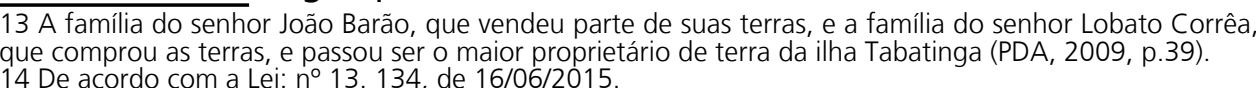


do um grupo de pessoas ${ }^{15}$, o qual pediu apoio ao Movimento dos Sem Terra - MST e, participaram da reunião no INCRA naquele momento para discutir sobre o documento da terra, que legitimava direitos sociais de comunidade tradicional, com seus pescadores artesanais, extrativistas e agricultores familiar. Nessa reunião, ficaram sabendo que, de fato, a ilha estava sendo pleiteada por vários empresários do município de Abaetetuba. Sobre essa questão, seu Zeca, morador da ilha, relata na entrevista, "A gente ficou preocupado porque se esses empresários conseguissem regularizar a ilha para eles, no caso para fazer turismo, a gente ia perder o local e, muitas pessoas não teriam onde morar (Seu Zeca, entrevista, 04/2018).

Vale dizer que os grupos sociais ainda hoje buscam participação e ações efetivas de direitos coletivos quanto a organização territorial dos sujeitos do campo, cujas ideias são polissêmicas e até multidimensionais, como os conceitos de desenvolvimento e território (SANTOS, 2008). O território da ilha Tabatinga é um exemplo de desenvolvimento territorial no bojo da reforma agrária controversa, na qual os projetos de Assentamentos não são diferentes pois, além de garantir o desenvolvimento regional e local, buscam o reconhecimento de seus territórios, quanto a necessidade de garantia de direito à terra. No intento pelo título da terra, o povo da ilha sabia que a área territorial é patrimônio da União e que teriam que se direcionar à Gerência do Patrimônio da União para requererem o título de propriedade, de ocupação e benfeitoria da Reforma Agrária. Assim, após os esclarecimentos da GRPU, oficializaram, através de requerimento, o pedido de titulação da terra e, a autorização para que o INCRA assumisse a responsabilidade de efetivar o projeto de Assentamento Agroextrativista na ilha.

No ano seguinte, 1999, juntamente com a equipe da Comissão Pastora da Terra - CPT região Guajarina, as lideranças da ilha travaram uma luta em busca de mais direitos, dessa vez trataram do amparo ao projeto de Assentamento para ribeirinhos. Tão logo ficou pronto, encaminharam documentação pertinente até a Câmara dos Deputados Federal, INCRA Nacional e GRPU/nacional ${ }^{16} \mathrm{e}$ a vitória veio no final de 1999 ano, quando receberam os documentos informando que a emenda foi aprovada. $O$ povo ribeirinho estaria incluso em projetos de populações tradicionais, mesmo com a distinção entre área ribeirinha e a ideia de projetos agroextrativistas, "visto que nós éramos ribeirinhos e morávamos a muitos anos na beira do rio, só que nunca tivemos direitos sociais garantidos, porque não existia lei, mas com aprovação da emenda passamos ter direitos a Reforma Agrária" (Seu Zeca, entrevista, 04/2018).

Em 2000, conviveram sob o gerenciamento do INCRA com o processo de documentação e identificação da ilha a partir do levantamento cartográfico, georreferenciamento, o mapeamento socioeconômico das famílias e no

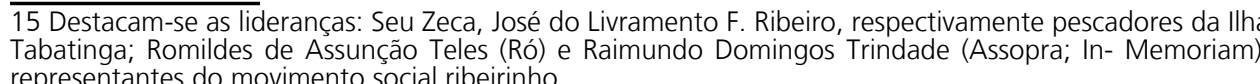
16 Nesse momento se depararam com a situação de inexistência de Lei que amparasse os ribeirinhos no
projeto da Reforma Agráría. A luta continuou na tentativa da revogação da mencionada lei. cartório regional. Nesse sentido, houve várias reuniões com os moradores e os diversos movimentos e organizações sociais envolvidos, direcionando a documentação das famílias a serem cadastradas no projeto de assentamento. A ilha Tabatinga, foi a primeira ilha do Estado do Pará a ser beneficiada por projeto de reforma agrária no Brasil. Outra exigência legal para efetivação dos tramites do projeto foi a constituição de uma associação da comunidade, sendo criada, em 06/08/2004, a Associação do PAE Nossa Senhora do Livramento - ASPANSLI, a qual atualmente é a gerenciadora e representa o povo da llha Tabatinga.

\section{- Despescando ${ }^{17}$ saberes do povo ribeirinho da área Costa Tabatinga}

Os pescadores artesanais da comunidade Costa Tabatinga, além dos saberes vinculados aos recursos naturais e as formas sustentáveis de produzi-los, sabem construir alguns instrumentos de trabalho.

Faz parte da tradição do lugar a produção familiar e ainda encontra-se viva na experiência do povo. Sob o aprendizado dos antepassados, a pesca do camarão é desempenhada por membros e segundo uma organização da família, isto é, o pai, a mãe, os filhos sempre participaram das atividades produzidas para sua subsistência. No dizer de um morador "sempre foi uma agricultura continuada" (Seu Zeca, entrevista, 04/2018). São práticas socializadas entre parentes e entre vizinhos, enquanto "aprendizado" do saber e ensinar dentro do processo de trabalho, como demonstrado no quadro abaixo.

\begin{tabular}{|c|c|c|c|}
\hline Produção familiar & Tipos & Quem prática? & Período \\
\hline Pesca & Camarão (Macrobrachium amazonicum) e peixe. & Pai, Mãe e filhos & Ano todo \\
\hline Extrativismo & Açaí (euterpe oleraceae), miriti (mauritia flexuosa) & Pai, Mãe e filhos & Por safra \\
\hline Criações de pequenos animais & Porco, pato, galinha, peru & Mãe e filhos & Ano todo \\
\hline Coleta de sementes & Andiroba, ocuúba & Mãe e filhos & Não se pratica mais \\
\hline Extração da borracha & Leite & Mãe e filhos & Não se pratica mais \\
\hline Artesanato & Paneiro, matapi, rasa, brinquedo de miriti & Pai, Mãe e filhos & Alguns meses do ano \\
\hline Plantas medicinais & Hortelã, ouriza, arruda, anador, cipó alho, etc & Mãe e filhos & Ano todo \\
\hline Frutas & Manga, jambo, abiu, limão galego, cupuaçu, ingá, miriti, etc. & Pai, Mãe e filhos & Por safra \\
\hline
\end{tabular}

As famílias envolvem-se nas atividades e, dependendo do tipo, durante o ano todo ou não. A atividade depende do período que cada produção é realizada, por exemplo, em conexão com tempo de cultivo, da chuva, do verão, das marés, das fases da lua. Tais configurações sociais e ambientais são elementos que determinam a vida e o trabalho dos sujeitos que vivem da pesca, em particular a pesca do camarão regional. Passamos, então, ao saber-fazer dessa atividade. 17 Diz respeito a ação de retirada do camarão do matapi, realizada pelo próprio pescador ou outros sujeitos
da familia. 
A prática cotidiana do pescador artesanal encontra-se imbuída de um saber diferente do saber escolar, cuja aprendizagem e transmissão se dá no âmbito informal, relacional e dirigida quase sempre a uma necessidade, "o meu pai aprendeu a pescar com meu avô e, nós aprendemos com meu pai, pescar de matapi, de rede, de espinhel e a cultivar as fruticulturas" (Seu Zeca, entrevista, 04/2018). Sobre essa dimensão do aprender um saber, Brandão (2009, p. 2-3) pondera que: "A regra do saber é a de que o primeiro aprendizado se dê no interior da família nuclear, do grupo doméstico ou, por extensão, da parentela, entre gerações contínuas ou alternadas". Os pescadores artesanais do local aprendem a pescar fazendo na prática, isto é, praticando.

Normalmente, os moradores nasceram em meio a esse aprendizado, assim quando crianças observavam seus pais, na curiosidade de aprender, se envolviam com aquele fazer. $\mathrm{Na}$ interpretação do aprender, Brandão (2009, p. 22) menciona que: "Com os olhos presos no fazer dos adultos, eles fazem também e aprendem. $O$ saber flui sem o ensino e, às vezes, parece que quanto menos é evidente, tanto mais é efetivo". Os ribeirinhos da comunidade Costa Tabatinga, também atuam em relações de ensinar-e-aprender da mesma forma que o autor menciona em sua pesquisa. Vejamos o que diz seu Zeca, "a gente aqui da ilha aprende a pescar olhando ou com o outro, praticando, porque já tenho mais de 35 anos pescando. Sou nascido e criado praticando pesca e vou me aposentar na pesca, porque não sei fazer outra coisa a não ser pescar" (Seu Zeca, entrevista, 04/2018).

Circulando entre os sujeitos e entre grupos familiares, o conhecimento popular se constrói envolto nas experiências e trocas vividas pelos moradore e, dessa forma, adquirem valores, ensinam saberes, aprendem cotidianamente, protagonizam construções vitais e a se manter sujeitos ribeirinhos com seus saberes e suas práticas culturais. E, para além da escola e para o aprender:

Proponho que o busquemos seguindo pequenas tilhas de situações vividas e biografias confessadas. Busquemos surpreender através delas e de mestres e discípulos que entre si ensinam aprendem, o mistério do processo pelo qual o saber se transmite, em meio a gestos e alas que aparentemente submergem que afinal serve o ensino que ali se faz (BRANDÃO, 2009, p. 2).

Com base nesse referencial e tomando as observações do trabalho de campo, é possivel dizer que o modo como se constrói o saber está muito atrelado a estrutura familiar dos ribeirinhos, perpassando várias gerações. Também, eles destacam a ausência de não saber ler e nem escrever, mas que mesmo assim o saber e o aprender se processava entre as pessoas e na comunidade. "Meu pa nunca sentou num banco de escola mais sabia muito de agricultura" (Seu Zeca, entrevista, 04/2018). Dominam processos de gestão da vida produtiva, como vender seus produtos com a mesma compreensão de quem é alfabetizado. Ele fazia uma conta na cabeça que era mais do que uma máquina, sabia quanto dava três quilos de camarão, ou grama dava um dom que Deus deu para ele, por que ele não aprendeu com ninguém (Seu Zeca, entrevista, 04/2018)

Na comunidade, os pescadores manifestam continuamente em sua dinâmica diária o esforço, a dedicação e o aperfeiçoamento, mantendo toda uma prática do saber-fazer que consiste na relação entre familiares e vizinhos, cuja pesca do camarão com matapi é uma de suas técnicas mais utilizada por eles. A forma como se constrói o instrumento de trabalho é bem peculiar e com base na necessidade de uso no trabalho e, a essência desse fazer (confecção) está presente no modo operante de trabalho deles. Ou seja, os utensílios utilizados em suas atividades de trabalho passam pelo saber popular e científico cuja construção de tais instrumentos tem significado para o pescador.

O matapi é produzido da matéria prima vegetal, a tala do jupati ${ }^{18}$, que pelo processo de secagem, num período entre quinze a vinte dias, e só depois está pronta para a fabricação do utensílio. Atualmente, mesmo os moradores conheçam a espécie e seu processo, "não existe a espécie de jupati na ilha Tabatinga" (Seu Zeca, entrevista, 04/2018) e, por isso, os matapis utilizados na comunidade são oriundos da região do Marajó e vendidos no comércio da cidade. Outra matéria prima que utilizam é o cipó de garachama, o conhecido cipó titica (Heteropsis flexuosa) (IDATAM, 2015). Pode ser confeccionado com fibra de plástico para fazer o tessume ${ }^{19}$ do pano do matapi dando firmeza as talas, e o funil ${ }^{20}$ que tem o formato de um cone, os quais completam as suas partes, conforme aparece nas imagens abaixo.

\section{Foto 1 - Matapi de fibra de plástico}

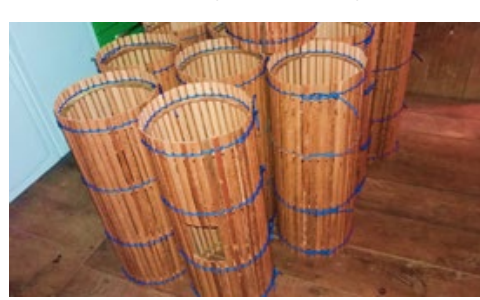

Fonte: BAIA, E. M. F., Jun. 2018

Outra espécie também muito parecida com o jupatí é o miriti típico dessa região de ilhas que é usado na construção do artesanato e outros diversos tipos de objetos, como a construção de brinquedos de miriti. A tala retirada serve para fabricação de paneiros, rasas, tipitis, mão de juda, abanos e outros. A diferença entre as duas espécies, jupatí e miriti, é que elas produzem frutos, mas somente $O$ miriti é comestível, sendo o fruto chamado de buriti, saboroso e bastante usado na culinária ribeirinha da comunidade e em outras ilhas de Abaetetuba.
18 Arvore do jupatizeiro (Raphia Taedigera) (IDATAM, 2015).

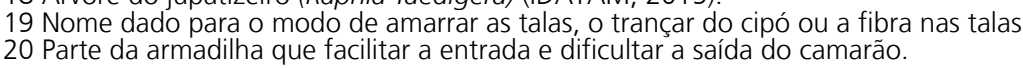


Inicialmente, o uso do matapi passa pela arte do iscar ${ }^{21}$, cuja ação envolve também a preparação e montagem da poqueca ${ }^{22}$, que é feita de babaçu e de outras misturas como o farelo ou coco ralado. Após o matapi iscado, os pescadores se deslocam em canoas ou cascos em direção aos igarapés, rios e às margens ou as beiras da baia. Além desse tipo de pesca, eles praticam outras formas como a pesca de lanço ${ }^{23}$, da gapuia ${ }^{24}$, do espinhel25, de rede, de caniço ${ }^{26}$ e a tapagem ${ }^{27}$.

Esses tipos de pesca, conforme já mencionado, envolve toda a família homens, mulheres e crianças, de forma que algumas atividades exigem esforço físico ou mais dedicação. A pesca de rede, de espinhel e de lanço são mais praticadas por homens, enquanto as mulheres realizam mais a pesca da gapuia e do caniço e no caso da pesca da tapagem realizam homens e mulheres. As mais comuns na comunidade pesquisada são a pesca do camarão com matap e da rede, que acontece diariamente com intenso fluxo de reciprocidade e de valorização por parte dos pescadores. Em se tratando da pesca do camarão, na comunidade, ela é realizada pelas mulheres e muitas vezes pelos filhos e filhas. Eles e elas atuam no preparo da isca, do $\operatorname{arriar}^{28}$ o matapi às margens dos rio e, até mesmo, agem no processo de comercialização.

A quantidade de camarão capturado depende muito da quantidade de matapis dispostos n'água. Geralmente, a captura ocorre em uma média de quinze a cinquenta matapis por pescador. Na sequência, algumas horas após arriar o matapi, este é retirado d'água levando em conta o tempo e o tipo de maré, o que pode ocorrer cedo da noite (madrugada) ou ao arraiar do dia (manhã). Nesse momento, ocorre o que os moradores conhecem e tem apropriação: a despesca. Normalmente se processa na ponte (ou trapiche) das residências dos pescadores ou em algumas situações quando o matapi fica permanente às margens dos rios ou, ainda, na beira de praias nos varais. Essa retirada ou despesca do camarão é feita também na canoa ou casco. $O$ camarão é armazenado em paneiros ou basquetas de plástico e a produção é comercializada na beira, outra parte é consumida pela própria família.

Nesse modo de pescar com o matapi e nas demais formas estão envolvidos todo um simbolismo amazônico que o pescador protagoniza e reinventa em sua prática, são manifestações míticas com os muitos costumes, lendas e histórias narradas por pessoas, quase sempre os mais antigos. Das histórias, contam da $\operatorname{lara}^{29}$, da cobra grande, do boto, mantendo vivo a cultura imaterial.

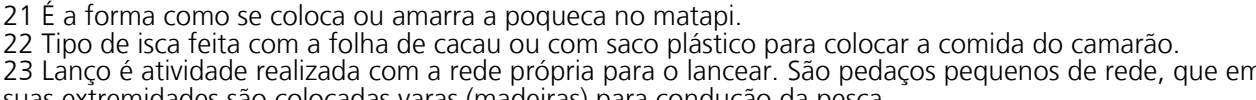

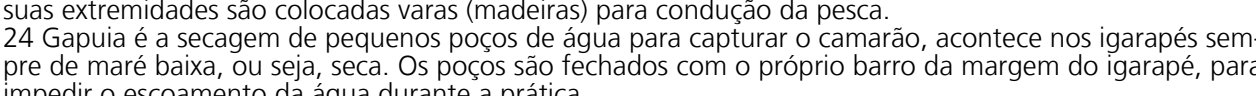

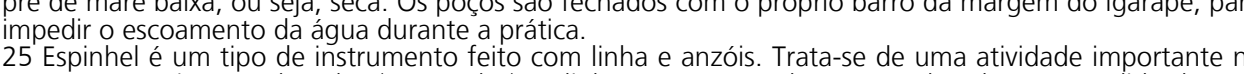
25 Espinhel é um tipo de instrumento feito com linha e anzóis. Trata-se de uma atividade importante na
pesca, os anzóis sáo colocados (estruvados) na linha com espaco de una ou duas bracas, medido de uma
man a outra, sendo oue o tamanho da linha varia conforme o local onde se vai pescar. O essinhel é colocamasa outra, sendo que o tamanho da inha varia contorme o local onde se vai pescar. O espinhel e coloca
do com pedras nas extremidades para fixar no fundo do rio. 26 Caniço também conhecido como vara de pescar. E produzido com galho de árvore e linha de nálon mais um anzol na extremidade da linha.

27 Tapagem é a forma de cerca que interrompe a passagem do peixe, que ocorre nos igarapés ou beira de

$29 \mathrm{~A}$ lará é conhecida como a mãe d'agua, linda mulher que encanta e protege as águas. A cobra grande,
Por esses mitos contestam e opinam sobre a mata e as áquas, fazem circular o conhecimento popular refletido a partir das diversas atividades dos pescadores.

Devido as experiências do cotidiano, o pescador conhece os tipos de marés que são ou estão propícias para a atividade da captura do camarão. $\mathrm{Na}$ maré de lua se tem muita fartura, ela é conhecida como lua cheia, sendo mais propícia para a pesca e podem ser também chamadas de maré de água morta. Nesta fase da lua, é o período mais indicado para capturar o camarão e, quando está graúdo ${ }^{30} \mathrm{e}$ em maior quantidade. Na conhecida maré de escura o camarão falha ${ }^{31}$, não tem a luz para o camarão flutuar na água, "porque o que faz o camarão flutuar até a superfície da maré é a lua" (Orêncio Vasconcelos, entrevista, 06/2018). Outra maré não adequada para a atividade da pesca, de acordo com a fala do seu Orêncio "é a maré tapecuema, é uma maré ruim para os pescadores, até porque chama muito a atenção do boto e de outros tipos de bichos ou coisas, além do pau que sobe na enchente e desce na vazante, quando pega o espinhel leva tudo".

Esse tipo de pesca é bastante discutido pelos moradores no que diz respeito a safra e a venda. Por exemplo, na visão do pescador Nereu Baia "Infelizmente o camarão não é mais como antigamente, que se colocava trinta matapis e pegava dez, quinze quilos de camarão. Hoje se coloca cinquenta matapis, não pega um quilo, pois o camarão foi embora, sumiu" (entrevista, 06/2018). Os pescadores atribuem isso à poluição do ambiente na localidade e na região Tocantina. Afirmam que as grandes empresas instaladas no polo industrial da Vila dos Cabanos, região do município de Barcarena, são as grandes responsáveis pela poluição dos rios de Abaetetuba, especialmente o que vem ocorrendo nas ilhas, prejudicando a vida dos pescadores artesanais e de ribeirinhos que atuam na pesca e utilizam as águas que banham os rios, furos e igarapés. Sobre essa questão, os entrevistados da comunidade Costa Tabatinga se posicionam:

Nas nossas ilhas e em nossas águas a gente tinha muito camarăo em abundância, mas a partir da poluiçáo dessas grandes empresas a gente sentiu muita dificuldade e ate hoje não teve mais safra de camarăo. Estamos próximo da safra do camarão e, hoje, o camarăo que e vendido em grande quantidade na feira de Abaetetuba não é da nossa localidade, o camarão ficou restrito, ja năo tem com tanta frequência como antigamente (Nereu Baia, entrevista, 06/2018).

Naquele tempo o trabalho era sempre em beira de praia, a pesca de rede de espinhel, de matapi. Na epoca era muita farta, pegava muito peixe. Se vinha alegre para a beira fazer a venda porque a fartura era grande (Orêncio Vasconcelos, entrevista, 06/2018).

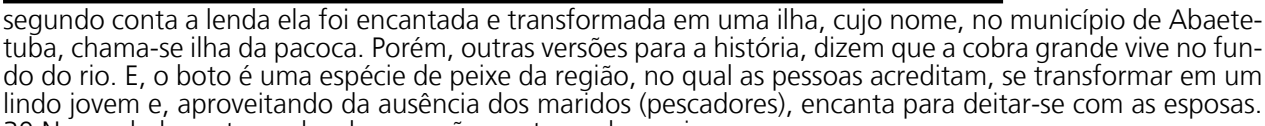

30 Nome dado ao tamannho do camaráo em tamanho maior.
31 Falha se refere a quantidade de camarào pescado, em quantidade pouca. 
Consequentemente, mudou a inserção deles nesse tipo de pesca, mudou a abundância do pescado. Atualmente, muitas espécies de pescados não são mais encontradas na região, por exemplos espécies como o filhote e o dourado são hoje raros, devido a migração para outro local por causa da poluição. Seu Zeca diz que "é uma situação difícil. A gente hoje coloca o espinhel e o que se pega é muito lixo, sacola plástica, copos descartáveis, é tudo, com isso afugenta ${ }^{32}$ o peixe, o camarão" (entrevista, 04/2018).

$\mathrm{Na}$ comunidade são efetivamente quarenta mulheres e quarenta e sete homens que praticam a pesca artesanal na comunidade Costa Tabatinga, sendo que desse quantitativo "muitos não possuem o registro Geral da Pesca RGP" (Manoel Correa, entrevista, 05/2018) 3. $^{33}$. Sao eles e elas que garantem o sustento de suas famílias e, ao mesmo tempo, protagonizam a luta em defes da vida comunitária com interesses comuns, além de manterem-se no território perspectivando a gestão de políticas sociais geradoras de qualidade de vida, como os projetos de assentamento e o seguro defeso. Na fala do Secretário da colônia Z14

O pescador tem muito a ver com a luta, porque na época a gente vivia e ganhava apenas o que a gente trabalhava e, com a luta política dentro do Assentamento e através da Colônia de pescadores. Se conseguiu a vitória do direito a receber o seguro defeso, e dessa forma conseguimos colocar vários peixes no defeso que não tinha ate então, não tinha defeso nenhum, agora tem (Manoel Correa, entrevista, 05/2018)

Além do seguro defeso de direito do pescador artesanal, existe ainda o direito à aposentadoria por tempo de trabalho ou por invalidez. Tais benefícios são gerenciados pela colônia de pescadores artesanais, em documentos registrados em órgão estadual e nacional que legitima a profissão de pescador, dando autoria as práticas culturais e cotidiana desses sujeitos.

\section{Considerações Finais}

A prática educativa vivenciada por pescadores ribeirinhos se faz alicerçada em suas experiências de vida por diferentes sujeitos, em diversos mo mentos da prática social e durante o ciclo produtivo de trabalho no âmbito da pesca, do extrativismo, da agricultura. E, no tocante a pesca do camarão, conforme descrito e apresentado alguns dados, trata-se de um saber produtivo, ancestral e imbricado aos condicionantes do ambiente natural. Na pesca, os sujeitos envolvidos agregam trocas simbólicas, modos operantes, estratégias de economia, exercícios sustentáveis, fazendo circular um conhecimento que extrapola a negativa de saber ler e escrever. No caso, a prática artesanal da 32 Afugenta expressão usada para dizer que o peixe ou camarão foi embora do local.
33 Esse quantititativo é referente ao total de moradores, que são 92 homens e 96 mulheres Fonte: IDATAM,
2015 . pesca com matapi vem assegurando a permanência e garantindo a sustentabilidade das famílias, conforme foi pormenorizado no texto.

Tal atividade dinamiza-se em dinâmicas informais de ensinar e aprender, construídas em momentos da pesca propriamente e, durante a preparação desta. Ali acontece uma prática educativa de forma continuada, no local e constitui-se uma manifestação da cultura daquele povo. Ficou explícito que os moradores locais ao potencializarem tal prática, potencializam processos de: transmissão do saber ou na vertente teórica de Brandão (2009) de fazer circular o saber; ação coletiva entre e intergeracionais como formas outras de sociabilidade humana; movência de aprendizagens mútuas em que a sobrevivência é a inspiração comum e de luta por parte dos envolvidos.

A discussão aqui trazida buscou associar a cultura e o modo de vida de sujeitos ribeirinhos em interlocução com as ideias postuladas para a educação do campo que busca se organizar e se produzir. Sobre isso, importa articular conhecimento escolar e saber popular, os quais, perpassando por uma prática emancipadora, podem vir a ressignificar memórias, identidades e histórias vividas dos sujeitos e, desse modo, articular dimensões sociais visando separar a opressão e as diversas cercas do analfabetismo, da fome e a falta de projetos emancipadores para/com o homem e a mulher do campo.

Assim, pode-se assegurar que esta prática educativa desenvolvida no lugar, possibilita caminhos para se pensar a construção de uma educação escolar que valorize as produções e modos culturais presentes na realidade social do território. A educação não se restringe ao espaço escolar, ela está em diversos ambientes da comunidade e, tais condicionantes de aprendizagem precisam estar dispostos para novas configurações do processo educativo formal. Políticas públicas voltadas para as realidades territoriais que se coadunam com o 'mundo das águas' precisam tomar o fortalecimento de identidade cultural e de transformação social dos sujeitos do campo em especial, dos pescadores da ilha Tabatinga.

\section{Referências bibliográficas}

ARROY, M. G.; FERNANDES, B. M. A educação básica e o movimento social do campo: Articulação Naciona Por uma Educação Básica do Campo. Editora: Zenaide. Brasília, dezembro de 1999.

BRANDAO, 2007, p. 11-27.

Saber e aprender a saber na Cultura Popular o exemplo de foliões de Santos Reis e de Folgazões do São Gonçalo. Editora Santuário (Idéias e Letras). Aparecida do Norte, 2008/2009. p. 1-33.

BRASIL. LEI No 13.134, DE 16 DE JUNHO DE 2015. www.planalto.gov.br. Acesso em jun de 2018.

CASTRO, E. R. de. Território, Biodiversidade e saberes de Populações Tradicionais. Papers do NAEA, nº 092 Belém, maio/1998. p. 4-16.

CPT E MORIVA. Memória e revitalização identitária: Ribeirinho e Ribeirinhas da llhas de Abaetetuba. Org. CPT Região Guajarina, novembro/2009.

DIEGUES, A C O Mito Moderno da Matureza Intocada. In. As Representaç̃es do Mundo Natural, o Espaço 
A PESCA DO CAMARÃO COMO UMA PRÁTICA EDUCATIVA NO PROJETO DE ASSENTAMENTO AGROEXTRATIVISTA NOSSA SENHORA DO LIVRAMENTO ILHA TABATINGA, ABAETETUBA-PA

Público, o Espaço dos "Comunitários" e o Saber Tradicional. 5a ed. São Paulo: Hucitec/Nupaub-USP. 2004. p. 63-98.

FRAXE, T. de J. P.; et al (org.) A agricultura familiar: principal fonte de desenvolvimento socioeconômico e cultural das comunidades da área focal do Projeto Piatam. In: Comunidades ribeirinhas amazônicas: modos de vida e uso dos recursos naturais. Manaus: EDUA, 2007, p. 55-87.

Instituto Brasileiro de Geografia e Estatística - IBGE. 2017. In: https://cidades.ibge.gov.br/brasil/pa/Abaetetuba. Acesso em jun. de 2018.

Instituto de Desenvolvimento e Assistência Técnica da Amazônia - IDATAM. Autodiagnóstico do Projeto de Assentamento Agroextrativista Nossa Senhora do Livramento. Abaetetuba - PA. Outubro/2015.

Instituto Nacional de Colonização e Reforma Agrária - INCRA, SR 01, Belém- PA, 2015.

MACHADO, J. R. C. Terras de Abaetetuba. Organização do autor. Belém, 1986.

MINAYO. M.C. (org). Pesquisa social teoria método e criatividade. 28aed. RJ: Vozes 2009. p. 7- 29.

MOLINA, M. C. Educação do Campo e Pesquisa: questões para reflexão. Brasília: Ministério do Desenvolvimento Agrário, 2006. 152 p.

PLANO DE DESENVOLVIMENTO DO ASSENTAMENTO - PDA. Projeto de Assentamento Agroextrativista Nossa Senhora do Livramento. Abaetetuba-Pará-Brasil/2009.

POJO, E. C. Gapuiar de saberes e de processos educativos e identitários na comunidade do rio Baixo Itacuruçá, Abaetetuba-PA. 2017. Tese de Doutorado - Instituto de Filosofia e Ciências Humanas, Universidade Estadual de Campinas, Campinas.

POJO, E. C.; BAIA, E.; SILVA, J. Uma travessia pelas águas de Abaetetuba: notas de um percurso etnográfico. In: RIBEIRO, J. O. S. et al. (Org.). A pesquisa no Baixo Tocantins: Contribuições Teórico-Metodológicas. 1 ed. Curitiba-PR: Editora CRV. 2013.

POLLAK, M. Memória e Identidade Social. Estudos históricos. Rio de Janeiro, vol. 5 a 10, 1992, p. 200-212.

SANTOS, C. A. dos. Educação do Campo: campo e políticas públicas. Brasília: Incra; MDA, 2008. p. 39-65.

SALGADO, Mayany Soares. Modo de Vida Ribeirinho e Conhecimento Tradicional: uma análise das ações do PAE Nossa Senhora do Livramento na Ilha Tabatinga para fins de desenvolvimento local Abaetetuba-Pá. Belém-Pá. 2014. 118 p.

TOLEDO, V. M.; BARRERA-BASSOLS, N. A etnologia: uma ciência pós-normal que estuda as sabedorias tradicionais. Revista: Desenvolvimento e Meio Ambiente, v.20 (2009).

\section{Entrevistas:}

BAIA, N. P. Entrevista a Elza Baia. Abaetetuba, [06/2018]

BAIA, J. L. F. Entrevista a Elza Baia. Abaetetuba, [06/2018]

CORREA, M. L. Entrevista a Elza Baia. Abaetetuba, [05/2018]

FERREIRA, J. M. V. (zéca). Entrevista a Elza Baia. Abaetetuba, [04/2018]

RIBEIRO, J. do L. F. Entrevista a Elza Baia. Abaetetuba, [05/2018]

VASCONCELOS, O. da S. Entrevista a Elza Baia. Abaetetuba, [06/2018] 